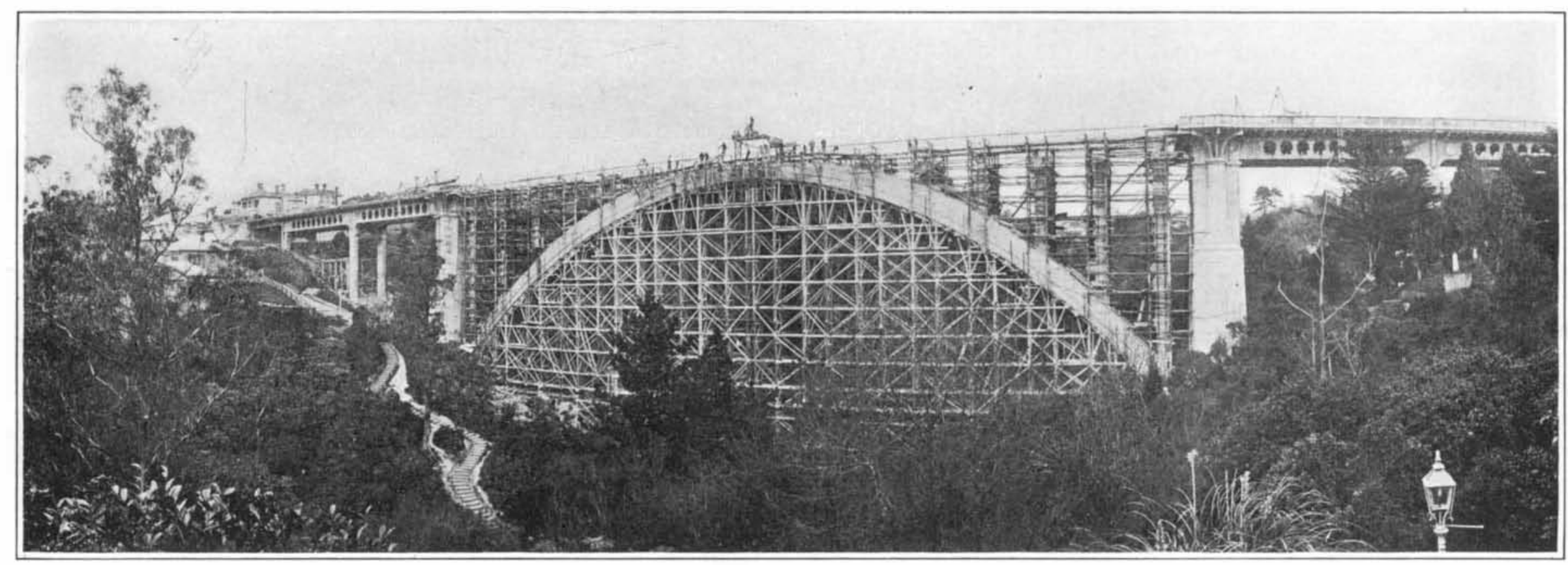

The Grafton bridge, Auckland, New Zealand, under construction.

\title{
Bridge Building in New Zealand
}

\author{
Interesting Designs That Have Been Successfully Erected
}

\section{By Oliver Johnson}

In several parts of New Zealand what are known as Dawson suspension bridges are being erected of which Joseph Dawson, of IHukanui, Paliatua, is the designer and builder. At the official opening of the bridges in the Marlborough Province a thirteen-ton traction engine was driven on to one of the structures and only the very slightest oscillation was visible while the engine was moving. It stopped in the center of the bridge when a test of the deflection was taken. With over 150 people on the structure, besides the engine, the deflection registered was under $1 \frac{1 / 4}{4}$ inches, which in itself is an eloquent testimony to the stability of the bridge, especially when it is taken into consideration that the deflection of an ordinary truss bridge is anything up to 4 inches. The deflection on the shorter bridge was under 1 inch.

The bridges, which span a yawning ravine about 170 feet in depth, are situated on the Seddon-Molesworth road, and are about twelve miles from the township of Seddon. The structures are spectacular and the practical test given them should dispel any doubts as to their efficiency. It was admitted by practical as to their efficiency. It was admitted by practical
men at the funetion that the bridges were all that men at the function that the bridges were all that $\mathrm{Mr}$.
Dawson claimed for them-the acme of solidity, durabłlity and cheapness.

The bridges are of similar design and are respertively 104 and 94 feet in length. The anchors anc towers are of concrete, which gives the structures solid appearance. The anchor rods pass through iron pipes embedded in the concrete and are fixed at th back of the concrete with large iron washers and double nuts, which can be replaced should necessit arise. The rods are two inches in diameter and upse two and a half inches at the threads. They are fixe to the cables which have a solid thimble spliced in each end, with strong iron straps and bolts. The clips on each side of the thimbles have $17 / 8$-inch bolts pass ing through them and flrmly screwed up. There are four cables, which have each a breaking strain of 85 tons, or collectively, 340 tons. Each anchor has breaking strain of 66 tons, and the eight rods togethe are capable of sustaining a weight of 588 tons. The cables are 5 inches in diameter and pass over the towers on cast iron saddles with six strong iron wheel towers on cast ir sades whee to each cable. The suspending rods that carry the
bridge from the cables are composed of steel, 1 inch in bridge from the cables are composed of steel, 1 inch in
diameter, and are spaced at intervals of 5 feet and flxed to the cables with strong clips. They each hav a breaking-strain of 14 tons. The steel channel that holds the concrete decking is double with a space left between to receive the suspending rods which are screwed to the bottom. From the flange of the channe curved corrugated iron is put at 5 feet centers to re ceive the concrete deck, forming a series of arches throughout the bridge, which has a camber of from 1 to 8 inches. A top dressing of 4 inches of concrete is put on making a solid deck. The trusses or chord are double - that is, there are two chords on either side of the bridge, spaced 1 foot apart, so that the cables

\section{TAIHAPE BRIDGES.}

(an go between the double trusses, which are 5 feet high and have a $5 \times 4$ timber top and bottom, with galvanized iron pikes between spaced to 5 feet centers. The truss bolts are $3 / 4$-inch iron and the only timber in the bridge is the top and bottom chords and the wheel guards. Over a space of 10 feet there are six rods with a breaking strain of 84 tons. With the weight of the bridge taken from the rods there are 79 tons over a space of 10 feet, upon which a traction engine rests. The crushing strain of the towers is 2, tons, the breaking strain of anchor rods 528 tons, and the suspending rods 532 tons. One of the bridges fully loaded would have a weight of about 65 tons, but it would have a margin of safety five times that weight. One cable would sustain the whole weight and leave 20) tons to spare.

To the layman it would appear that a wooden bridge could be erected at a cheaper rate than one of ferroconcrete, but this is not so. The bridges at Upton Downs cost, with commission added, $£ 7: 12: 9$ per foot, while a wooden suspension bridge erected at Mt. Bruce (ost £11 per foot.

Two lofty massive ferro-concrete towers of enormou strength and solidity stand as sentinels on either side. f'rom these the eight steel cables support the bridge heing attached at each of the approaches to anchor rods embedded in concrete and capable of taking a strain of 1,000 tons. The combined strength of the cables is 672 tons, while the bridge itself weighs but (i) tons. There are 124 suspending rods $7 / 8$ of an inch in diameter, and these are capable of bearing a strain of 1,036 tons. Compared with the bridge built by the Government at Mt. Bruce, which weighs 70 tons and has a span of only 220 feet, the Taroa bridge is vastly superior in weight carrying capacity although 10 tons lighter in weight.

$$
\text { THE HUTT BRIDGE. }
$$

The length is 175 feet, width 12 feet, weight of bridg empty 65 tons. About 30 tons of cement have been used. The four towers are of reinforced concrete connected by arches between the piers. There are twelve wheels on each tower-forty-eight in the whole. There are eight cables connecting and supporting the bridge; each has a breaking strain of 72 tons riveted together at 5 feet center; the arches of corrugated iron between channels are filled with reinforced concrete deck. The channels form a series of arches right through the center of the bridge. The camber of bridge is 18 inches from tower to tower. The truss is 5 feet over all and is composed of iron and steel-no wood whatever being found in final structure. The suspending rods are of $7 / 8$-inch thick iron. All the rest of cord bolts $5 / 8$-inch thick; $13 / 4$ pipes are put at every 5 feet to convey the strain of the bolts. The blocks that support the suspending rods from the cable are of reinforced concrete The cables are all attached to substantial concrete anchors let into the bank; each cable is 280 feet long.
THE GRAFTON ARCH BRIDGE, AUCKLAND

The most interesting feature of the bridge, from the engineering point of view, is the 320 foot arch span. The adoption of an arch of that span was unique in the history of reinforced concrete work, inasmuch as the largest known span was 280 feet, that over the Rocky River, U.S.A. Another unique feature is the length and depth of the main girders in both approach spans. These girders range from 75 feet to 80 feet in span, and at one approach these spans form one continuous girder of 306 feet, which is considered to be the longest in the world. The span is supported by sets of piers. The deepest point of the gully is 147 feet from the road level. The roadway is 24 feet wide, and is covered with Neuchatel ásphalt. The footways are each 6 feet wide, and are finished in concrete. The balustrades are in reinforced doncrete, and the kerbing in Coromandel stone. The bpídge is illuminated by twenty-six electric lights, in each of which are two 25 candle-power incandescent lamps.

A very large quantity of material was used in the construction of the bridge-over 5,200 cubic yards of concrete, and 330 tons of steel. In the mixing of the concrete, 1,130 tons of cement were used, and 2,100 cubic yards of broken blue-stone, as well as 4,050 cubic vards of shingle, 60 cubic yards of sand for rendering, and 230 yards (cubic) of stone boulders. The timber used in the arch span, centering and falsework, totaled 400,000 superficial feet

Mr. IR. F. Wood, C.E., was chief engineer to the Ferro Concrete Company, of Australasia, Limited, at the time tenders and designs were asked for by the City Council, and he decided to submit a design of a very bold nature, taking as a model the bridge which crosses the Isar River, near Gruñwald, Bavaria, built by the firm of Wayss \& Freytag, Neustadt. This bridge consists of approaches with 30 foot span girders and two three-hinged arches 230 feet clear span. The general appearance of this work is very graceful, and he decided that a design after this bridge would be very fine if it could be carried out at the cost, or for the money available, $£ 35,000$. After making a careful survey of the bedrock that would have to support the foundations of the big arch, and measuring carefully the angle of thrust and the stratification of the sandstone rock, several preliminary sketches were made, and he finally decided after careful investigation to design one arch over the gully of 320 feet clear span, this being the distance giving the best result, keeping in view the angle of thrust of the arch and the sweep, which would all be regulated by the proportion of rise of arch from its springings to the crown to the span, which worked out very nearly as four of span to one of rise, and which formed a curve closely approximating a parabola, but which is not generally considered by engineers to be a curve possessing any beauty. The approaches consist of one small span, 41 feet at one end, and two large spans, 80 feet each, straight girders, hollowed out for the nurpose of lightening and the gen- 


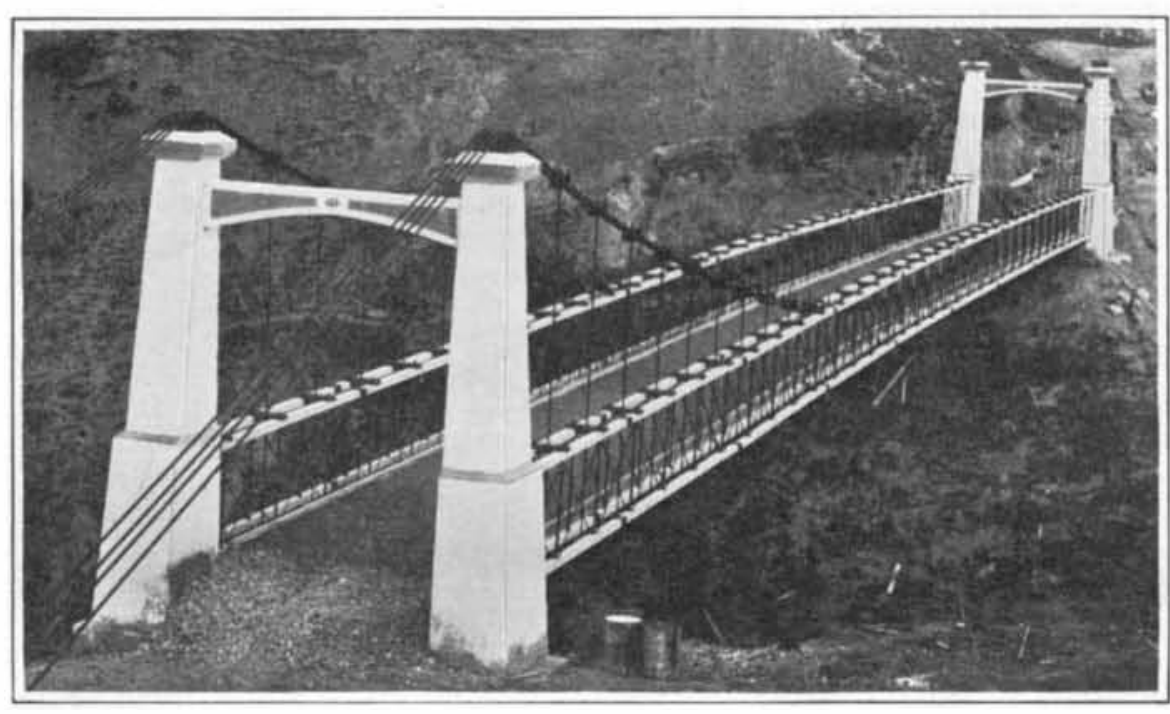

Ashley-Clinton suspension bridge.

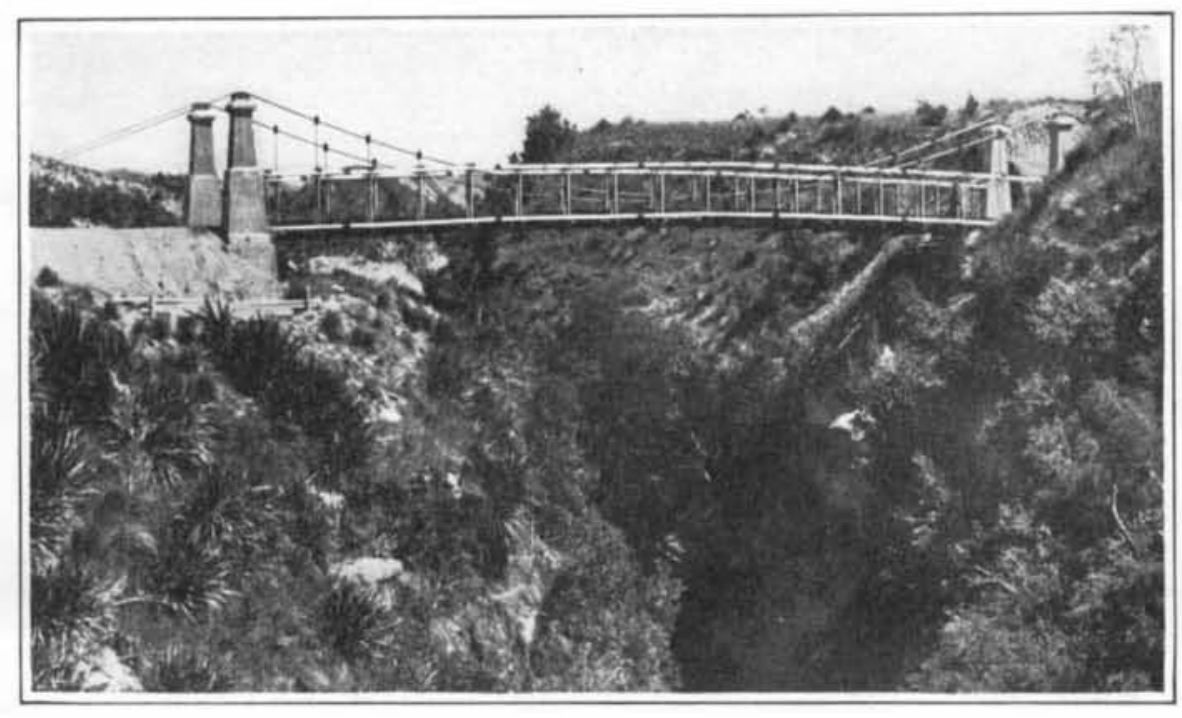

Bridge across Upton Downs gorge. cril appear:unce. Une ent consists of two spans of 3i feet each and four splans of 75 feet each. The ends (f) eatch end girler are free to slide when expanding or contracting, but are continuous over their pier supports in between, and in the calculations were treated as such in each case. The large girders are three in number in each bay, and measure 9 feet, 3 inches deep by 15 inches wide, carrying the proper amount of steel reinforcement to take up all the necessary calculated stresses. The secondary beams and decking are more or less just the ordinary type of reinforced concrete

The main piers are more for architectural effect, and in no way carry any portlon of the main arch. These piers are 100 feet high, 50 feet by 25 feet at the bottom, tapering to 16 feet by 36 feet at the top; are hollow from top to bottom, and only support the end of each girler from the approaches. 'The main arch has a span if 320 feet between the hinges, and a rise of 87 fet, and consists of two arch rings, braced together by heavy wind ties to prevent racking. The size of the rings, or ribs as they are termed, vary from 6 feet by 4 feet 6 inches at the skewback hinge to 9 feet 6 inches by 4 feet 3 inches at the haunch and 5 feet by 4 feet at the crown hinge. The arch was built on Oregon pine falsework centering, which amounted to 400,00 superficial feet in all, and the ribs were built in blocks weighing rrom 15 to 35 tons, placed alternately from the crown lownwards to the abutments, the column blocks being the first moulded; the alternate, or filling, blocks, being the wind bracing blocks, being also moulded from the crown towards the abutment. The crown hinges were put in last. The whole of the concrete work for the arch ribs and wind-bracing took fourteen days. The columus rising from the arch ribs are $\mathrm{T}$ shaped, with $T$-shaped bracing or tie beams. The reinforcement in these columns is very heavy, to prevent any possible lateral bending of the column.

The arch ribs are hooped with 1/4-inch steel rods every 12 inches apart, but more heavily at the fourth or toward the skewback hinge. 'The longitudinal reinforcement beyond, being of material assistance, wis really never seriously taken into consideration, the arch being designed to act entirely in compression, and is consequently truly a masonry arch, with three hinge to allow the proper movement to take place for ex pansion and contraction. Had the true reinforced or elastic arch been designed, the shape would have been entirely different, and the reinforcement considerably heavier. The pressure due to thrust of the arch is taken II) by the hinges and distributed throughout the conrete by means of steel $\mathrm{H}$ girders, riveted together to form grids, which were buried in the concrete. Th height of the arch above the bottom of the gully is 147 eet, the span 320 feet, the width of roadway 24 feet ind two pathways, each $f$ feet, making a total of 36 feet between parapets. The weight of the arch and superstructure is about 3,700 tons. The pressure upon the abutments at the rock base is two tons per square foot when loaded. The total length of the bridge is 0i1. feet, being one of the largest masonry structures in the world.

\section{X-Rays and Crystal Structures, With Special Reference to Certain Metals}

ON THE occasion of the sixth annual May Lecture of the Institute of Metals, at a meeting of the Institute in London, Prof. W. H. Bragg, D.Sc., F.R.S. (Nobel Prizeman), gave an interesting account of the new method of applying the properties of X-rays to the study of erysta structure, including the structure of certain metals.

The method, it was shown by the professor, results in the determination of the exact relative positions of the atoms of which the crystal is composed. It is not successful in every case as yet, because of the lack of practice and experience of the experimenters in the new field and
because some of the interpretations are not fully underbecause some of the interpretations are not fully under-
stood. There is no lack of indications; but we are not yet fully aware of the meaning of all of them.

It is natural to attack first such crystals as have no obviously simple structure and consist of few elements associated in simple proportions. It is also of great adassociated in simple proportions. vantage if the crystals belong to a group of isomorphous members, such as the rock-salt series. This series, in fact, has everything to recommend it to the experimente -its form is simple, that of the cube; its symmetry high; it contains two elements only, in equal proportion e. g., sodium or potassium associated with ehlorine or iodine; and there are several members of the series, so that we can watch the effect of changing one element at a time. The constitution of this series was, therefore one of the first to be examined and made plain.

The constitution of the diamond, which has also been determined, presented a rather more difficult task, because the arrangement of the atoms is not so simple as that of the rock-salt series: although its form is eubic, its symmetry is high, and it contains atoms of one kind. Of the metals which will naturally be of special interest to the Institute of Metals, silver and copper, and by inference gold, have been shown to possess a very simple structure, in which the atoms are arranged as in the piling of shot. Bismuth and antimony have a distorted arrangement; but these two, as well as zinc, have not been completely determined. A brginning had been made with iron. The war has, however, stopped all work of the kind on this metal.

This new field of research, according to Prof. Bragg, depends on a principle already known. When a regular train of wases falls upon a surface separating two media, part is reflected and part goes on. If the part that goes on meets another separating surface, a second portion is reflected and some of this emerges from the second medium in the same direction as the beam reflected from the first surface. It will happen in genera! that the two reflected beams are out of phase and to that extent destroy one another. Whether they do so or not depends upon the relation between the wave-length, the angle of the inclination of the beam to the reflecting surfaces, and the distance between the surfaces. In this way are explained the colors of the soap film, of the thin wayer of oil on the surface of a liquid, of the colors of steel when being tempered, and so on

If the reflecting surfaces are many in number, not two, the effect is made more intense and at the same time more precise. It occurs in the beautiful colors of potash erystals as shown by Lord Rayleigh. These crystals are formed of alternating layers, twinned across their surfaces of separation, and for some obscure reason the thickness of all the layers is the same though it varies from erystal to erystal. When white light containing all wave-lengths is incident upon such a erystal, at a certain angle, then only that wave-length is reflected for which the proper relation between the wave-length, angle, and spacing holds good. If the angle is altered the wave-length which is reflected is no longer the same. Hence the play of colors which the crystal shows.

It is an essential cause of the success of this wonderful effect that the wave-length and the spacing are not very different in amount.

We now pass on to the case of the X-rays. These consist of waves-so, indeed, these very experiments tell uswhich are something like ten thousand times shorter than the wave-length of light. To obtain the parallel effect we must look for reflecting surfaces which are ten thousand times closer together than the twinning surfaces of the chlorate of potash crystals, and these are separated from one another by only the forty-thousandth of an inch or thereabout. These also nature has provided in the layers of atos in the crystals.

It may seem curious that a layer of atoms should act as a reflecting surface: but after all it is not necessary that such a surface should be continuous. A row of iron railings, for example, can act as a reflector of sound waves. A natural face of a crystal contains, no doubt, a layer of atoms arranged regularly; and behind the natural face are other layers all similar, and placed at regularly inereasing distances behind it. Thus, all the conditions for this peculiar reflection experiment are present, and we actually find that when a pencil of X-rays of a definite wave-length are allowed to fall upon the face of the crystal, and the crystal is gradually turned round so as to alter the angle of incidence, the reflection of the beam as a whole is non-existent, except when the angle is right. Then it flashes out strongly. When this angle is observed, th. $\theta$ relation of the wave-length to the spacing is known.

The instrument used is called the X-ray spectrometer. It has no lenses because $X$-rays cannot be refracted, and the rays are invisible, so that in place of the telescope appears a chamber containing gas, which is ionized by the X-rays. The resulting electrical effect is observed in an electroseope. It is important that the measurement of the result is quantitative, so that in this respect the new spectrometer has an advantage over the old.

In this way, if we use always the same X-ray, we can compare the spacings between the layers parallel to one after another of the natural faces parallel to the crystal; and in this way we arrive finally at the crystal structure. The instrument is not at all difficult to use, and the observed effects are large and precise, so that it is quit easy to get numerical results. The interpretation is not always quite so easy. One part of it comes readily, vi\%. the number of molecules to each unit of the pattern of the crystal-the unit heing the smaller part, which, being reflected again and again without alteration of orienta tion or distance from its the complete sulphate contains four molecules; the unit of pattern of antimony contains two atoms.

The far greater difficulty lies in the determination of the way in which the atoms are arranged in the unit. These data are sufficient, but the interpretation is hard. To understand how it is attempted, and in some case achieved, is best explained by models.-Chemical Nevis.

\section{Mysterious Swarm of Moths}

In the report of the South African Museum for 191: just issued, Dr. L. Péringuey, the director, relites: very extraordinary occurrence. While the troops of the Union were camped in the wide sand-belt of Luderitzbucht and Swakopmund, waiting to adrance inland, there appeared, suddenly, after heavy rains-a thin almost unheard of in those parts-all along the line, mmense swarms of moths. The fact is the more extraordinary and mysterious since these sands are almost void of visible regetation. That they were brought by the wind from inland Dr. Perig probable. They disappeared as rapidly as they came. Samples which were sent to the museum proved to consist of no fewer than twenty species of Noctuidae. In this report mention is also made of the fossilized skul of the "Boskop" man found in the 'Transvaal, and of fragments of limb-bones, probably of the same skeleton. This skull, which seems to be remarkable for its great ength, has not yet been described in detail. It is much to be hoped that this will soon be done. A mandible found in the river-gravels at Harrismith, and stone implements found in another locality in th Orange Free State, are also mentioned among the acquisitions for the year deserving special mention.-Natur 

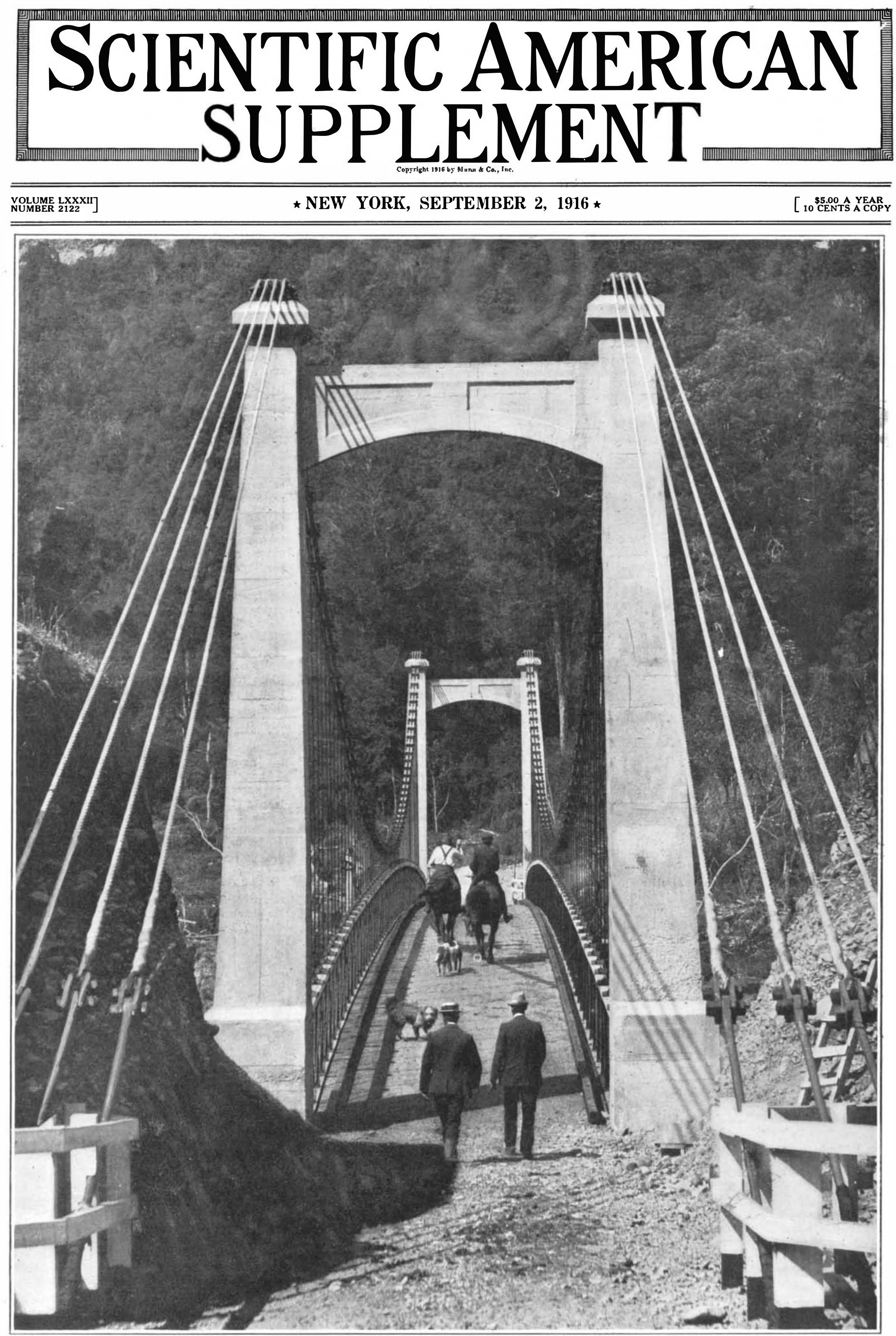

An allractive suspension bridge of simple design that spans a chasm 170 leet deep.

BRIDGE BUILDING IN NEW ZEALAND.-[See [age 152.] 